\title{
Welke barrières ervaren bedrijfsartsen bij het gebruik van de richtlijn Psychische problemen?
}

Evelien Brouwers, Marjolein Lugtenberg, Karlijn van Beurden, Berend Terluin, Jaap van Weeghel, Jac van der Klink, Margot Joosen

\section{Samenvatting}

Eerdere onderzoeken toonden aan dat de NVAB-richtlijn Psychische problemen in de praktijk zeer weinig gebruikt wordt. Dit artikel geeft een overzicht van de barrières die bedrijfsartsen ervaren bij het gebruik van deze richtlijn.

31 bedrijfsartsen bespraken in zes groepen de inhoud en aanbevelingen, in acht bijeenkomsten. De geluidsopnames werden letterlijk uitgeschreven en met software voor kwalitatief onderzoek geanalyseerd.

Gebrek aan kennis van de richtlijn bleek een cruciale barrière te zijn voor gebruik in de praktijk. Ook wisten bedrijfsartsen vaak niet hóé ze de richtlijnaanbevelingen konden opvolgen. Daarnaast waren er praktische barrières en vond men het lastig om oude gewoonten te veranderen. Ze voelden zich in meerdere opzichten niet in staat gesteld om de richtlijn te volgen.

De voornaamste barrières die bedrijfsartsen ervaren kunnen worden verholpen door meer scholing in kennis en vaardigheden, door het verbeteren van IT-systemen en door bedrijfsartsen meer tijd en ruimte te bieden om volgens de richtlijn te werken.

Richtlijngebruik, Veel werknemers zitten erg lang thuis als ze zijn uitgevalPsychische len met psychische problemen. Langdurig ziekteverzuim problemen, kan negatieve gevolgen hebben voor enkele belangrijke Kwalitatief domeinen van kwaliteit van leven, zoals financiën.

onderzoek

Dr. E.P. Brouwers is senior onderzoeker arbeid en psychische gezondheid bij Tranzo, Tilburg University.

Dr. M. Lugtenberg is postdoc onderzoeker bij de afdeling Maatschappelijke Gezondheidszorg van het Erasmus Medisch Centrum, Rotterdam.

Dr. K.M. van Beurden is datamanager bij de afdeling klinische epidemiologie van het Leids Universitair Medisch Centrum.

Dr. B. Terluin is senior onderzoeker bij de afdeling Huisartsgeneeskunde en Ouderengeneeskunde van het Amsterdam Public Health research institute, VU Medisch Centrum, Amsterdam.

Prof. dr J. van Weeghel is hoogleraar rehabilitatie en participatie van mensen met ernstige psychische aandoeningen bij Tranzo, Tilburg University.

Prof. dr. J.J. van der Klink is hoogleraar duurzaam inzetbaarheid en psychische gezondheid bij Tranzo, Tilburg University.

Dr. M.C. Joosen is senior onderzoeker arbeid en psychische gezondheid bij Tranzo,

Tilburg University.

Correspondentieadres:

e.p.m.brouwers@tilburguniversity.edu
Om werknemers die verzuimen met psychische problemen beter en sneller terug naar werk te begeleiden heeft de NVAB in $2000^{1}$ een richtlijn ontwikkeld, die herzien is in 2007. ${ }^{2}$ Eerder onderzoek toonde aan dat gebruik van de richtlijn door bedrijfsartsen samenhing met een kortere verzuimduur bij werknemers met overspanning ${ }^{3}$, milde stress gerelateerde problemen ${ }^{4}$ en veelvoorkomende psychische problemen in het algemeen. ${ }^{5}$ Echter, verschillende onderzoeken hebben aangetoond dat deze richtlijn in de praktijk slechts zeer matig gebruikt wordt.,7

Er zijn dus mogelijkheden om verzuim door psychische problemen sterk te beperken, maar deze mogelijkheden worden in de praktijk niet gebruikt. Hoe komt dat? In dit artikel doen we verslag van het onderzoek naar de vraag welke barrières bedrijfsartsen ervaren bij het gebruik van de richtlijn Psychische problemen.

\section{Methoden}

\section{Onderzoeksopzet}

Dit kwalitatieve onderzoek was onderdeel van een grote gerandomiseerde gecontroleerde trial naar de effectiviteit van een nascholingstraining voor bedrijfsartsen in het toepassen van de richtlijn. ${ }^{8}$ Dit grotere onderzoek bestond uit twee groepen: een experimentele groep die de nascholingstraining kreeg, gericht op het verhelpen van barrières voor richtlijngebruik, en een controlegroep die dat niet kreeg. De deelnemers van het in dit $T B V$ artikel beschreven onderzoek waren alleen de 31 bedrijfsartsen die de nascholing volgden (de experimentele groep). Alle bedrijfsartsen waren werkzaam bij dezelfde grote arbodienst in Nederland. De nascholingstraining was ontwikkeld op basis van recente inzichten uit de implementatieliteratuur. ${ }^{9}$ De training bestond uit acht interactieve bijeenkomsten voor zes kleine groepen (vijf tot zeven bedrijfsartsen). De bijeenkomsten duurden elk twee uur, en waren verspreid over één jaar. Tijdens de training werd de richtlijn uitvoerig besproken. Er werd ingegaan op hoe de aanbevelingen van de richtlijn zich verhielden tot de gebruikelijke werkwijzen van de bedrijfsartsen, en welke barrières gebruik van de richtlijn in de weg stonden. Uitgangspunt van de training was 
om bedrijfsartsen zélf na te laten denken over hun eigen werkwijzen en te bepalen in hoeverre en op welke punten deze overeenkwam of afweek van de richtlijn. Er was tijdens de bijeenkomsten veel ruimte voor discussie en feedback tussen bedrijfsartsen onderling. Wanneer bedrijfsartsen bepaalde aanbevelingen beter wilden gaan opvolgen werd gewerkt met een plan-do-check-act cyclus ${ }^{9}$, waarbij werd geoefend en geëvalueerd. Deelnemende bedrijfsartsen waren zeer positief over deze nascholingstraining en gaven in een nameting aan meer zelfvertrouwen te hebben bij de begeleiding van mensen met psychische problemen, en het bovendien leuker te vinden om hen te begeleiden. ${ }^{9}$

\section{Data analyse}

Van alle trainingsbijeenkomsten werden geluidsopnames gemaakt. Vervolgens werden deze letterlijk uitgeschreven en door twee onderzoekers met behulp van het kwalitatieve softwareprogramma Atlas.ti geanalyseerd. ${ }^{10}$ Er werd gekozen om in eerste instantie 50\% van de transcripten kwalitatief te analyseren en vervolgens na te gaan of er geen nieuwe inzichten meer werden bereikt (ofwel of er datasaturatie was bereikt, in termen van kwalitatief onderzoek). Dit bleek inderdaad het geval; de overlap in barrières en oplossingen was groot. In totaal werden 21 trainingssessies van twee uur geanalyseerd. Voor het categoriseren van de barrières werd het model van Cabana et al. gebruikt als basis ${ }^{11}$, indien nodig aangevuld met nieuwe barrières. In dit model wordt onderscheid gemaakt tussen drie grote categorieën: kennisgerelateerde, attitude gerelateerde en externe barrières. Meer gedetailleerde informatie over de analyses is te vinden in het Engelstalige artikel. ${ }^{10}$

\section{Resultaten}

De 31 bedrijfsartsen volgden alle acht bijeenkomsten van de training. Zes bedrijfsartsen konden één keer niet aanwezig zijn en haalden deze bijeenkomst in een andere trainingsgroep in. De gemiddelde leeftijd van de deelnemers was 53 jaar (SD 4,3) en zeventien (55\%) bedrijfsartsen waren man. Gemiddeld hadden ze 21 jaar (SD 7.1) werkervaring als bedrijfsarts en werkten 33 uur per week (SD 5,6). 28 (90\%) hadden eerder (na-)scholing ontvangen in de richtlijn Psychische problemen.

\section{Ervaren barrières}

Op drie terreinen werden problemen ervaren die goed gebruik van de richtlijn in de weg stonden: kennis-, attitudegerelateerde- en externe barrières. Deze worden hieronder toegelicht.

\section{Barrières op het gebied van kennis \\ 1.1 Bedrijfsartsen kenden de inhoud van de gehele richtlijn niet goed}

Hoewel bedrijfsartsen vooraf vaak zelf dachten de richtlijn vrij goed te kennen bleek uit een kennistest en gedurende de training dat dat niet het geval was. Bedrijfsartsen bleken een gebrek aan kennis te hebben van alle vier onderdelen van de richtlijn.

\subsection{Bedrijfsartsen waren vaak niet op de hoogte van bestaande hulpmiddelen}

Ze wisten vaak niet van het bestaan van bij de richtlijn behorende tools en andere hulpmiddelen.

\subsection{Veel bedrijfsartsen kenden de kern van de richtlijn niet}

Een aantal bedrijfsartsen was niet op de hoogte van de meest centrale uitgangspunten van de richtlijn, zoals dat de nadruk vooral zou moeten liggen op het evalueren van het herstel (procesgerelateerde evaluatie) in plaats van op tijdscontingent werken.

\section{Barrières op het gebied van attitudes}

Er waren vier veel besproken barrières op het gebied van attitudes.

\subsection{Weerstand tegen richtlijnen in het algemeen}

Een aantal bedrijfsartsen vond dat er te veel bureaucratie gemoeid was met richtlijnen en vond het volgen ervan daarom te veel gedoe. Ze gaven aan behoefte aan vrijheid te hebben om niet uitsluitend volgens modellen en schema's te hoeven werken. Daarnaast hadden sommigen ook weerstand specifiek tegen de richtlijn Psychische problemen omdat ze vonden dat deze niet goed toepasbaar was:

"Ik merk ook dat ik-ik wil het wel volgen, maar niet strikt. Ik wil vrijheid hebben in wat je tegenkomt. Omdat $i k$...ik bedoel: de praktijk is gewoon niet te vatten in zo'n richtlijn. Het is altijd anders of ingewikkelder of moeilijker."

\subsection{Niet weten hoe het te doen}

Bedrijfsartsen hadden vaak het gevoel niet in staat te zijn om specifieke richtlijnaanbevelingen op te volgen. Ze misten specifieke vaardigheden; wisten niet hóé ze het moesten doen. Zo gaven ze bijvoorbeeld aan het moeilijk te vinden om de werkomgeving van de zieke werknemer te adviseren of overtuigen en ontbrak het hen aan hulpmiddelen hiervoor:

"Ik weet nog steeds niet hoe ik aan leidinggevenden uit moet leggen in een half uur... ik wil ze graag begeleiden en hen laten zien hoe ze beter zouden kunnen omgaan met de situatie. Als ik er dan iets verstandigs over wil vertellen dan heb ik misschien een half uur de aandacht, maar dan moet het ook afgelopen zijn, denk ik. En hoe kan ik ze in een half uur iets vertellen, zodat ze...ja, iets beter met hun mensen omgaan en misschien eens de aandacht hebben en wat vragen gaan stellen van: wat 
is er aan de hand, wat.. welke oorzaken zitten er in het werk, waar kan ik je bij helpen, wat heb je nodig?"

\subsection{Geen hoge verwachting van de uitkomst van het} eigen handelen volgens de richtlijnaanbevelingen Zo dacht een aantal bedrijfsartsen dat het toepassen van structurele terugvalpreventie in de praktijk weinig verschil zou maken, omdat het bedrijf verder toch niets zou doen met hun advies:

"Ik heb een school eh, waar een directeur zit die (...) totaal geen invoelend vermogen heeft en heel lomp omgaat met zijn medewerkers.... Ik heb er eerst met hem zelf wel over gesproken eh, in nette bewoordingen uiteraard, en eh, daarna ook wel met de bovenschoolse directeur ja, die voert dan een keer een gesprekje met die man en doet er verder niks mee. Daar ben je toch van afhankelijk van hè, ik kan wel weer die bovenschoolse aanspreken 'ja, doe er eens meer mee' (...) Maar dat haalt dan weinig uit. (...) Ja, je bent toch beperkt dan uiteindelijk en daar moet je je ook gewoon bij neerleggen."

\subsection{Moeite met het doorbreken van oude gewoonten en routines}

Bedrijfsartsen gaven aan het moeilijk te vinden nieuwe dingen aan te leren, zoals het uitvoeren van een volledige probleemanalyse en procesdiagnose zoals aanbevolen in de richtlijn:

"Wat wel tijd kost is natuurlijk iets nieuws aanleren. (...) Weet je, en als je onder druk staat dan laat je dat los. Dan ga je lekker op je routine, waar je wel snel en efficiënt mee bent."

\section{Externe barrières}

Met externe barrières worden factoren bedoeld waarop bedrijfsartsen zelf geen directe invloed hadden maar die wel hun richtlijngebruik in de weg stonden. Veel bedrijfsartsen voelden zich niet ondersteund in het volgen van de richtlijn en werden gehinderd in het werken volgens de richtlijn door verschillende externe barrières.

\subsection{Hoge werkdruk en een gebrek aan tijd Dit was een frequent ervaren barrière voor richtlijn- gebruik:}

"Als je onder tijdsdruk werkt en dan komt iemand, dan denk je iemand met psychische problemen, ik heb nog vijf minuten of tien minuten, ik loop achter, dan denk ik: nou, ik geef hem een ferme, stevige hand en ik geef hem maar gelijk, blijf maar lekker thuis en zie je de volgende keer wel. Zou een redenatie kunnen zijn. Heeft niks meer met de regels der kunst te maken, het is totaal niet waar ik achter sta, maar het zou kunnen, uit zelfbehoud."

3.2 Bedrijfsarts mag vaak richtlijn niet volgen, wegens contracten afgesloten tussen arbodienst en bedrijven
In deze contracten wordt bijvoorbeeld bepaald hoeveel tijd de bedrijfsarts aan de werknemer mag besteden. Deze contracten lieten het soms niet toe om de richtlijn te volgen, bijvoorbeeld om de werknemer al in de eerste twee weken na ziekmelding te zien of om aan terugvalpreventie te werken.

\subsection{Ongebruiksvriendelijke computersystemen}

Er werd uitvoerig gesproken over de hinder die bedrijfsartsen ondervonden van ongebruiksvriendelijke computersystemen als barrière voor het werken volgens de richtlijn. Ook was het op verschillende locaties werken lastig voor het bij de hand hebben van de juiste hulpmiddelen om de richtlijn te volgen.

"Ik moet echt gewoon hup een lijstje er bij, en dat lijstje heb ik maar ja, ik zit op twintig verschillende plekken. Dus dat lijstje is voortdurend... Ja en je hebt dan een tas bij je met zoveel dingen die je allemaal moet meenemen."

\subsection{De veranderende rol van de bedrijfsarts}

Sommige bedrijfsartsen gaven aan dat de rol van de bedrijfsarts veranderd is (meer gericht op assessment) en daardoor niet meer past bij wat de richtlijn aanbeveelt.

3.5 Aanpak en het beleid van andere partijen (werkgevers, huisartsen, psychologen)

De visie en werkwijze van andere stakeholders bleken soms in strijd te zijn met de richtlijnaanbevelingen, of een goede samenwerking in de weg te staan:

"Dan gaat hij uiteindelijk naar de psycholoog. (...) Nou dan bel je die na acht keer op, zo van zit er onderhand een beetje schot in, wat je aan het doen bent, want anders stop er maar mee want dit levert niks op. Gaan we EMDR doen, ik zeg dat heb ik al wel drie keer voorgesteld, omdat die hele gebeurtenis die hij heeft meegemaakt toch redelijk traumatisch is, ook gezien zijn persoonlijkheid. Nee dat kan niet. Nou zijn we 10 keer verder, ja dan moet er toch maar EMDR komen (.....)"

\subsection{Angst voor misbruik van informatie of controle door} anderen

Bedrijfsartsen spraken over een terughoudendheid om de richtlijnaanbeveling op te volgen om bepaalde gegevens te noteren in het elektronisch patiëntendossier. Bedrijfsartsen waren bang voor misbruik hiervan en noteerden soms expres bepaalde informatie niet, of op een manier die alleen voor henzelf te begrijpen was.

\subsection{Vorm van de richtlijn: te veel informatie}

Bedrijfsartsen vonden het lastig om zowel een uitgebreide richtlijn te hebben, als een groot achtergronddocument, omdat ze daardoor geen overzicht meer hadden: "Het is wel ondoorzichtig vind ik ook. En ja, het is natuurlijk een hele uitgebreide richtlijn en daar hebben 
we dan hele grote achtergrondinformatiedingen bij nodig en ik denk dat dat het probleem is, om alles aan elkaar te koppelen zeg maar."

\subsection{Werknemergebonden factoren}

Bedrijfsartsen gaven aan dat werknemers soms een verborgen agenda hebben gericht op een specifieke uitkomst, wat het moeilijk maakt om een correcte diagnose te stellen:

"En dan begint ze mij te beschuldigen dat ik een slechte bedrijfsarts ben, dat ik nu in een kwartier tijd kan bepalen of zij aan het werk kan. En ze zegt zeer arrogant tegen mij, van, "Moet ik me even laten gaan voor u, dat u misschien ziet hoe ziek ik ben?" (...) En op dat moment beginnen ze te eisen dat ik met hun psycholoog contact zoek."

\section{Discussie}

Samengevat zijn er volgens de bij dit onderzoek betrokken bedrijfsartsen enkele belangrijke veranderingen nodig om het richtlijngebruik door hen te verbeteren.

Ten eerste gaven bedrijfsartsen aan meer en betere scholing nodig te hebben. Het huidige gebrek aan kennis van de richtlijn is een cruciaal probleem dat de uitvoering ervan belemmert. Naast scholing in kennis kan scholing in vaardigheden ook de onderhandelingspositie van de bedrijfsarts, als spin in het web van de re-integratiepraktijk, versterken. Bijvoorbeeld vaardigheden om werkgevers te overtuigen en te beïnvloeden. Scholing in kennis en vaardigheden kan bedrijfsartsen empoweren en nieuwe succeservaringen opleveren waardoor de soms (te) lage verwachting van hun eigen beïnvloedingsmogelijkheden in het re-integratietraject verminderen. Hierbij is het belangrijk dat de scholing aansluit bij de individuele behoeften van de bedrijfsartsen en dat er aandacht is voor daadwerkelijk veranderen van het gedrag van de bedrijfsarts in de praktijk.

Ten tweede is een verbeterslag nodig om IT-systemen gebruiksvriendelijker te maken. Hierdoor kan het volgen van de aanbevelingen vergemakkelijkt worden, bijvoorbeeld bij rapportage, het bij de hand hebben van hulpmiddelen en het werken op verschillende locaties. Gebruiksvriendelijkere IT-systemen kunnen bovendien de werkdruk van de bedrijfsarts helpen verminderen en daarmee het werkplezier verhogen.

Een derde stap die volgens de bedrijfsartsen gezet zou moeten worden is dat de bedrijfsarts meer ruimte en tijd krijgt van zijn/haar arbodienst om volgens de richtlijn te werken. Te krappe contracten tussen arbodienst en bedrijven gaan lijnrecht in tegen enkele belangrijke aanbevelingen van de richtlijn, en goedkoop lijkt hier duurkoop. Zo hangt frequenter contact tussen bedrijfsarts en werkomgeving bijvoorbeeld samen met snellere werkhervatting van de werknemer met psychische problemen ${ }^{12}$, maar daar moet de bedrijfsarts wel de ruimte voor krijgen.
In dit onderzoek werden door de bedrijfsartsen relatief veel externe barrières geïdentificeerd die het richtlijngebruik in de weg staan. Dat waren veelal barrières die arbodiensten zouden kunnen verhelpen; zij zouden dus hun voordeel kunnen doen met de uitkomsten van dit onderzoek. Maar ook anderen kunnen bijdragen aan de kwaliteit van zorg voor werknemers die uitvallen met psychische problemen. Zo is de NVAB al bezig met de herziening van de richtlijn, waarbij de bevinding dat de huidige richtlijn te omvangrijk en onoverzichtelijk is wordt meegenomen.

De resultaten van dit onderzoek moeten worden beschouwd in het licht van een paar beperkingen. Ten eerste is het onderzoek uitgevoerd onder een groep bedrijfsartsen die allen werkzaam waren bij dezelfde grote arbodienst. Het is daarom niet gezegd dat de bevindingen generaliseerbaar zijn naar zelfstandige bedrijfsartsen, of bedrijfsartsen in andere dienstverbanden. In samenhang hiermee moet opgemerkt worden dat dit een kwalitatief onderzoek was, waarbij generaliseerbaarheid niet het primaire doel is, maar waarbij het gaat om exploratie, zoals bij vragen als waaróm iets (niet) gebeurt. De resultaten van het onderzoek bieden daarom suggesties voor verbetering van het richtlijngebruik, zoals door bedrijfsartsen zelf geformuleerd. Of dat richtlijngebruik vervolgens leidt tot verbetering van de verleende zorg is - op basis van eerder onderzoek - wel te verwachten, maar zal nog moeten worden aangetoond. Het is aan de beroepsgroep om te kiezen hoe zij met het richtlijngebruik om wil gaan. Indien er daadwerkelijk ingezet wordt op het verhogen van het richtlijngebruik zal dit behoorlijk grote aanpassingen vergen in de werkwijze van de bedrijfsarts ten opzichte van de huidige werkwijze, wat ook grote repercussies heeft voor andere stakeholders zoals arbodiensten en werkgevers. De auteurs hopen dat dit artikel mede aanzet geeft tot het voeren van die discussie, in de eerste plaats binnen de beroepsgroep zélf en in de tweede plaats met de overige betrokken stakeholders.

\section{Dankwoord}

De auteurs willen graag de deelnemende arbodienst en bedrijfsartsen bedanken voor hun deelname aan het onderzoek, ZonMW voor de financiering van het project en Lian Snoeijen voor haar administratieve hulp.

\section{Disclosure}

Prof. dr. Jac van der Klink en dr. Berend Terluin zijn betrokken geweest bij de ontwikkeling van de richtlijn in 2000 en de herziening in 2007, en zijn als experts betrokken bij de richtlijnherziening die op dit moment door de NVAB wordt gerealiseerd.

Prof. dr. Jac van der Klink is parttime werkzaam bij de NSPOH. Deze organisatie is tevens partner van de Academische Werkplaats Arbeid en Gezondheid, waar ook Tranzo aan is verbonden. 
Dr. Evelien Brouwers was projectleider van het hier gerapporteerde onderzoek en de grotere trial naar de effectiviteit van de richtlijn. Ook is zij op uitnodiging van de NVAB voorzitter van de projectgroep en kerngroep die op dit moment de herziening van de richtlijn uitvoeren. Dit onderzoek werd mogelijk gemaakt door ZonMW, projectnummer 208030001.

Dit artikel is een bewerking (met toestemming) van het oorspronkelijk gepubliceerde artikel:

Lugtenberg M, Beurden KM van, Brouwers EP, Terluin B, Weeghel J van, Klink JJ van der, Joosen MC. Occupational physicians' perceived barriers and suggested solutions to improve adherence to a guideline on mental health problems: analysis of a peer group training. BMC Health Services Research 2016;16(1):271

\section{Literatuur}

1. Klink JJ van der, Dijk FJ van. Dutch practice guidelines for managing adjustment disorders in occupational and primary health care. Scand J Work Environ Health 2003;29(06):478 87.

2. Klink JJL van der, Ausems C, Beijderwellen BD, Blonk R, Bruinvels DJ, Dogger J, Hoedeman R, Janssen J, Loo M, Nieuwenhuijsen K, et al. Richtlijn: Handelen van de bedrijfsarts bij werkenden met psychische problemen, herziene uitgave. [Guideline: The management of mental health problems of workers by occupational physicians; revised version]. Utrecht: NVAB [Netherlands Society of Occupational Medicine]; 2007.

3. Nieuwenhuijsen K, Verbeek JHAM, Siemerink JCMJ, Tummers-Nijsen D. Quality of rehabilitation among workers with adjusment disorders according to practice guidelines; a retrospective cohort study. OEM. 2003;60 suppl 1:i21-5.

4. Rebergen DS, Bruinvels DJ, Bezemer PD, Beek AJ van der, Mechelen $\mathrm{W}$ van. Guideline-based care of common mental disorders by occupational physicians (CO-OP study): a randomized controlled trial. J Occup Environ Med 2009;51(3):30512.

5. Rebergen DS, Bruinvels DJ, Bos CM, Beek AJ van der, Mechelen W van. Return to work and occupational physicians' management of common mental health problems--process evaluation of a randomized controlled trial. Scand J Work Environ Health 2010;36(6):488-98.
6. Rebergen D, Hoenen J, Heinemans A, Bruinvels D, Bakker $\mathrm{A}$, Mechelen $\mathrm{W}$ van. Adherence to mental health guidelines by Dutch occupational physicians. Occup Med (Lond) 2006 Oct;56(7):461-8. Epub 2006 Jun 16.

7. Nieuwenhuijsen K, Verbeek J, Siemerink JC, Tummers-Nijsen D. Quality of rehabilitation among workers with adjustment disorders according to practice guidelines; a retrospective cohort study. Occupational and Environmental Medicine 2003;60(suppl 1):i21-i5.

8. Beurden KM van, Brouwers EP, Joosen MC, Terluin B, Klink $\mathrm{JJ}$ van der, Weeghel J van. Effectiveness of guideline-based care by occupational physicians on the return-to-work of workers with common mental disorders: design of a cluster-randomised controlled trial. BMC Public Health 2013;13:193.

9. Joosen MC, Beurden KM van, Terluin B, Weeghel J van, Brouwers EP, Klink JJ van der. Improving occupational physicians' adherence to a practice guideline: feasibility and impact of a tailored implementation strategy. BMC Med Educ 2015;15(1):82.

10. Lugtenberg M, Beurden KM van, Brouwers EP, Terluin B, Weeghel J van, Klink JJ van der, Joosen MC. Occupational physicians' perceived barriers and suggested solutions to improve adherence to a guideline on mental health problems: analysis of a peer group training. BMC Health Services Research 2016;16(1):271.

11. Cabana MD, Rand CS, Powe NR, Wu AW, Wilson MH, Abboud PA, Rubin HR. Why don't physicians follow clinical practice guidelines: a framework for improvement. JAMA 1999;282:1458-65.

12. Beurden KM van, Joosen MCW, Terluin B, Weeghel J van, Klink JJL van der, Brouwers EPM. Use of a mental health guideline by occupational physicians and associations with return to work in workers sick-listed due to common mental disorders: a retrospective cohort study. Disability and Rehabilitation 2017; Jul 7. doi:10.1080/09638288.2017.1347209. [Epub ahead of print]. 